\title{
La producción de objetos de concha recuperados en las ofrendas de Cobá, Quintana Roo
}

\section{The Production of Shell Objects Recovered in the Offerings of Coba, Quintana Roo}

\author{
Elva Adriana Castillo Velasco \\ Posgrado en Estudios Mesoamericanos, \\ Universidad Nacional Autónoma de México, México
}

\begin{abstract}
Resumen: Con el objetivo de reconocer las características de los objetos de concha que fueron ofrendados, entre el 250 y el 830 d.C., en la zona nuclear del sitio maya de Cobá, en Quintana Roo, se realizó el análisis formal, funcional y tecnológico de los mismos; ello ha permitido reconocer la producción de objetos diseñados especialmente para las ofrendas. Los resultados han mostrado también las relaciones que mantuvo Cobá con otras regiones, apoyando las evidencias encontradas en otros materiales y en los estudios epigráficos. La similitud en la forma y manufactura de algunos objetos arqueológicos de Cobá con los de otros sitios sugieren el desarrollo de producciones locales ligadas a una misma tradición regional.
\end{abstract}

Palabras clave: Cobá, objetos de concha, producción, estilo tecnológico, relaciones interregionales.

ABSTRACT: In order to recognize the characteristics of the shell objects that were offered, between 250 and 830 A.D., in the nuclear zone of the Maya site of Cobá, in Quintana Roo, we carried out its formal, functional and technological analysis; this has allowed us to recognize the production of objects specially designed for offerings. The results have shown also Coba's relations with other regions, supporting the evidence found in other materials and in epigraphic studies. The similarity in the form and manufacture of some archaeological objects of Cobá with those of other sites suggest the development of local productions linked to the same regional tradition.

KeYwords: Cobá, shell, production, technological style, interregional relationships. 
RECEPCIÓn: 11 de junio de 2019.

ACEPTACIón: 11 de agosto de 2019.

DOI: https://doi.org/10.19130/iifl.ecm.55.2020.0004

\section{El estudio de la producción}

El hallazgo de objetos arqueológicos elaborados en distintos materiales con diversidad de formas y asociados a contextos, épocas y culturas diferentes ha generado la inquietud de conocer los procesos que les dieron forma, así como sus usos y el contexto social en que fueron elaborados. De ahí que diversos investigadores se hayan preocupado por proponer elementos teórico-metodológicos que permitan conocer los diferentes aspectos de la producción.

La producción es concebida como el medio por el cual se realiza la transformación de recursos en elementos socialmente útiles y, por lo tanto, implica un conjunto de relaciones sociales organizadas, las cuales establecen las normas, los parámetros, las funciones, los valores, e incluso las propias necesidades; así como un conjunto de elementos materiales que permiten que dicha transformación sea posible (Mannoni y Giannichedda, 2004: 27-28; Costin, 2007: 148-150). Es en este sentido que la manufactura de objetos siempre se dará en el marco de un contexto específico que incluye el espacio y los aspectos sociopolíticos e ideológicos (Costin, 2007: 150). Al estudiar los aspectos tecnológicos de la producción, no sólo es posible reconocer los recursos materiales involucrados sino también las relaciones entre los individuos y su entorno, y el conjunto de tradiciones que dictan las formas de la producción. Como Herskovits (1954: 73-83) menciona, la tecnología es el medio que enlaza los aspectos económicos con los culturales y debido a que es el resultado de las tradiciones o costumbres que dan cohesión al grupo social, los cambios o fracturas en la estructura social y cultural se verán reflejados en ella igual que en la cultura material.

A través de la identificación de estilos tecnológicos, entendiendo por éstos la suma de elecciones que conforman el conocimiento de una cultura sobre la producción (Hohmann, 2002; Velázquez, Melgar y Hocquenghem, 2006), es posible comprender el sistema que la organizó, e incluso identificar lugares productores a partir de objetos terminados. Los estudios arqueológicos de concha centrados en la tecnología han tenido un largo proceso de desarrollo desde que Lourdes Suárez Díez (1974), sentara las bases para el estudio sobre sus procesos y técnicas de elaboración.

Desde hace casi 20 años este tipo de estudio se apoya en la arqueología experimental, lo que ha permitido acercarse al conocimiento de los procesos de manufactura y las herramientas empleadas para la elaboración de objetos en diferentes materiales asociados a grupos y épocas específicas, partiendo del supuesto de que todos los objetos son usados o producidos con esquemas determinados que les proporcionan características específicas; por lo tanto, el uso o producción de objetos similares siguiendo los mismos patrones deben dar los 
mismos resultados (Velázquez, 2012: 231). Así, la falta de indicadores directos del proceso de manufactura, tales como herramientas, desechos de producción, piezas en diferentes fases del proceso productivo, piezas falladas y reutilizadas, materias primas e instalaciones especiales (Hohmann, 2002: 38; Melgar, 2009: $14,15)$, es resuelta al caracterizar las huellas producidas experimentalmente con herramientas y técnicas específicas, siempre teniendo en cuenta la presencia en los sitios de instrumentos de trabajo o materiales asociados con las huellas de manufactura identificadas (Velázquez, 2012).

El Proyecto "Técnicas de manufactura de los objetos de concha del México prehispánico", ${ }^{1}$ ha implementado tal metodología para analizar colecciones de diferentes sitios y épocas, permitiendo identificar particularidades en la elaboración de los objetos y reconocer estilos tecnológicos propios de regiones y momentos específicos, la producción especializada y controlada por los grupos de élite de centros que dominaron en regiones y épocas determinadas, así como los cambios y continuidades dados a través del tiempo en los estilos tecnológicos asociados a la dinámica social (Velázquez, 2016).

\section{Referencias al estudio de material conquiliológico en la península de Yucatán}

El estudio de los materiales conquiliológicos recuperados en contextos arqueológicos de la región ha llevado a plantear preguntas sobre su aprovechamiento y formas de abastecimiento. Andrews (1969) reunió materiales de 18 sitios, con el fin de identificar la procedencia de las especies y con ello la evidencia de su comercio desde el Formativo. Al comparar las especies presentes en los sitios estudiados con su distribución natural reportada para entonces, planteó que el abastecimiento de moluscos se hacía desde la playa más cercana y que los moluscos que llegaban a sitios de tierra adentro lo hacían desde las costas que circundan la península de Yucatán. Cobos (2010) concluye lo mismo tras estudiar el material de siete sitios de la porción noroccidental de la península.

Tal modelo ha llevado a considerar que, por ejemplo, todos los ejemplares del género Spondylus presentes en colecciones de diferentes épocas de sitios distribuidos en la península corresponden con especies que habitan en torno a ella. Sin embargo, la revisión de colecciones antes no estudiadas contradice lo propuesto por Andrews y Cobos sobre un exclusivo abastecimiento local, dada la presencia de especies procedentes del Océano Pacífico como Spondylus crassisquama y Spondylus limbatus, incluso en sitios costeros. ${ }^{2}$

\footnotetext{
1 En adelante PTмосмP.

${ }^{2}$ Algunos sitios de la península en los que se han reportado especies del Océano Pacífico son: Xcambó (Velázquez y Melgar, 2014), Xuenkal (Alonso et al., 2013), cAlıcA (Castillo y Páez, 2015), Oxtankah (Melgar, 2009) y Calakmul (Colón, 2003; Melgar y Domínguez, 2014).
} 
Además de la identificación de especies utilizadas, el estudio de materiales conquiliológicos trabajados y sin trabajar reportados para todas las épocas en sitios costeros que circundan la península de Yucatán y en asentamientos de tierra adentro ha permitido reconocer formas que sugieren usos particulares tanto en el ámbito ornamental como utilitario. Ello ha generado clasificaciones tipológicas que permiten establecer relaciones entre materia prima y objetos terminados, el uso o consumo de los objetos por una determinada jerarquía social y reconocer los elementos del proceso de manufactura.

Siguiendo la metodología propuesta por el РтмосмP, se han analizado las huellas de manufactura en colecciones procedentes de diferentes sitios del área maya, lo que ha permitido determinar producciones especializadas de ciertos objetos como en el caso de Kohunlich (Reyes, 2010), o la producción de bienes exclusivos para grupos de élite y el control que éstos tenían sobre la producción, como en Calakmul (Colón, 2003; Melgar y Domínguez, 2014).

\section{El estudio de la producción de objetos de concha de Cobá}

Desde 1975, en el sitio arqueológico de Cobá se han recuperado numerosos objetos elaborados en concha, asociados tanto a espacios ceremoniales como habitacionales (Benavides 1981; Benavides y Manzanilla, 1987). Sin embargo, la presente investigación sobre su producción está sustentada en el análisis formal, funcional y tecnológico de los objetos de concha recuperados entre 1997 y 2013 por el Proyecto Cobá. ${ }^{3}$ Dicha investigación tuvo como objetivo identificar las particularidades de la producción (materia prima utilizada, técnicas de manufactura, diseño y uso o consumo) de los objetos de concha ofrendados en la zona nuclear de Cobá. Para ello, los 296 objetos que componen la colección fueron analizados en tres etapas: identificación biológica de la materia prima, clasificación tipológica de los objetos y análisis de las huellas de manufactura.

Con la asociación de estas características o particularidades se buscaba inferir la presencia de uno o más estilos tecnológicos, determinados por la asociación entre materia prima, tipo de objeto y herramientas empleadas en su manufactura. La presencia de estilos tecnológicos diferentes podría evidenciar cambios temporales y la presencia de diferentes centros productores, además de conocer las relaciones interregionales o las influencias culturales entre Cobá y otros sitios. De igual forma, las diferencias podrían estar marcando cambios temporales relacionados con los cambios políticos y económicos en la región.

\footnotetext{
${ }^{3}$ Proyecto de maestría "La producción de los objetos de concha recuperados en las ofrendas de Cobá, Quintana Roo", desarrollado dentro del Posgrado en Estudios Mesoamericanos, unam.
} 


\section{La ciudad de Cobá}

Cobá se localiza al noreste de la península de Yucatán, en la porción norte del estado de Quintana Roo, a $45 \mathrm{~km}$ al oeste de la costa del Caribe. Las primeras evidencias arqueológicas, cerámicas del horizonte Chicanel y el complejo Añejo, fechan su primera ocupación para el Preclásico Tardío (100-250 d.C.) (Benavides, 1981: 21, 22; Robles, 1990: 253-255).

El Clásico Temprano (250-600 d.C.) marca el inicio del desarrollo urbano que permitió la consolidación de la ciudad como capital regional en el Clásico Tardío (600-900 d.C.) hasta el año 830 aproximadamente, momento en que la ciudad habría alcanzado una extensión aproximada de $70 \mathrm{~km}^{2}$ con una población estimada entre 20,000 y 60,000 habitantes distribuidos en la zona nuclear y en los sitios “satélites" (Benavides, 1976: 93; Benavides, 1981: 22; Folan et al., 2009: 60; Benavides, 1987: 54; Con, 2007: 10-11; Pérez de Heredia y Biró, 2007: 20, 21). La ciudad se construyó siguiendo un patrón concéntrico con zonas bien delimitadas y con una marcada estratificación social (Benavides, 1981); el centro de este patrón lo constituye la zona nuclear, el área donde se concentraron los edificios de carácter administrativo y religioso (Benavides, 1981: 190).

Se ha planteado que el crecimiento de la ciudad se dio como resultado del control socioeconómico y organización de los grupos productores de sitios circundantes, y gracias a la expansión de un sistema político ligado con una tradición cultural que debió extenderse desde el área maya central (Navarrete, Con y Martínez, 1979: 82; Benavides, 1981: 207-210). La evidente planeación de la ciudad, su tamaño y la presencia de objetos procedentes de regiones distantes sugieren una organización social consolidada, capaz de administrar bienes y servicios para la población que habitó dentro y fuera de la ciudad, así como jugar un papel económico y comercial a nivel interregional (Benavides y Manzanilla, 1987: 22-23).

\section{Cobá en el ámbito regional}

Los materiales arqueológicos (cerámica, pedernal, obsidiana), la arquitectura, el estilo de las estelas y los estudios epigráficos han revelado los nexos que compartió Cobá con otros asentamientos del área maya tales como Tikal, Ek Balam, Río Bec, Naranjo, Motul de San José, Edzná y Uxul (Robles, 1990; Esparza, 2016). Si bien con algunos pudo establecer alianzas, como se infiere la hubo con Tikal durante el Clásico Tardío, con otros mantuvo una actitud beligerante (Esparza, 2016: 288, 295).

Las investigaciones en otros sitios del centro y norte de la península de Yucatán también han hecho evidente la amplia circulación de bienes y en muchos casos su conexión con el área del Petén, de ahí que se haya propuesto la existencia de dos grandes esferas culturales en el norte de la península: una al oeste 
(comprendiendo la mayor parte del noroeste y centro de la península, así como la zona Puuc) y otra oriental (que ocuparía el extremo este de la península) que formaría parte de un corredor comercial ligado con el Petén (Vargas, 1997: 143; Flores y Pérez, 2006: 89).

Si bien se sugiere que durante el Clásico la circulación de los productos entre regiones se dio principalmente por rutas terrestres, lo que permitía integrar más lugares favoreciendo el desarrollo de sitios que concentraban objetos locales y foráneos (McKillop, 1987), es posible que éstas se completaran con una ruta marítima además de las rutas fluviales (Arnauld, 1990). De esta manera, Cobá habría fungido como intermediaria de productos entre la región del Petén y Belice, y la porción noroccidental de la península de Yucatán, utilizando a Xcaret y/o Xelhá como puertos de desembarque para los bienes que llegaban vía marítima (Flores y Pérez, 2006: 89; Benavides, 1981: 210).

Hacia finales del Clásico Tardío las relaciones con el Petén empiezan a disminuir al tiempo que se incrementan las evidencias que la relacionan con sitios de la Costa del Golfo y norte de Yucatán (Maldonado, 1995: 84; Con, 2007: 12). La ausencia de tipos cerámicos característicos de Chichén Itzá, mismos que empezaron a extenderse por casi toda la península en ese periodo, sumada a la evidencia estilística, epigráfica e iconográfica, han llevado a plantear que Cobá tuvo su decadencia entre el 800 y el 830 d.C. (Pérez de Heredia y Biró, 2007: 20, 21).

\section{El proyecto Cobá y sus materiales de concha}

Desde 1992, el Proyecto Cobá ha realizado trabajos de excavación, liberación, restauración y mantenimiento en la zona nuclear del sitio (Con, 1996, 1998, 1999, 2005, 2010; Con y Ochoa, 2003, 2007; Con, Ochoa y Gómez, 2004), misma que tiene una extensión aproximada de $2 \mathrm{~km}^{2}$ y está formada por cinco grupos arquitectónicos: A o Macanxoc, B o Cobá, C o Nohoch Mul, D o Navarrete y Chumuc Mul (Benavides, 1981: 190) (Figura 1). De éstos, el grupo Cobá destaca por sus dimensiones y mayor antiguiedad, como lo sugiere la cerámica recuperada en las estructuras que lo componen y la sobreposición de etapas constructivas (Con, 1999).

En el extremo sur de la cancha del juego de pelota de este grupo se encontró una ofrenda compuesta por 119 objetos de concha, además de otros objetos de piedra verde, jadeíta, obsidiana y pirita (Con, 1998, 2000: 39). Los materiales cerámicos del complejo Añejo, recuperados en el juego de pelota, sugieren que fue construido durante el Clásico Temprano, por lo que la ofrenda correspondería con este periodo (Con, 2000: 31). Entre los objetos que componían la ofrenda destacan cuatro perfiles humanos, elaborados tres en concha y uno en piedra verde, así como dos manos cerradas con el índice extendido, ambas de concha; objetos similares se han reportado en otros sitios, como Xcaret (Con, 2000: 39), Comalcalco (Schmidt, de la Garza y Nalda, 1999: fig. 197) y Xcambó (Velázquez 


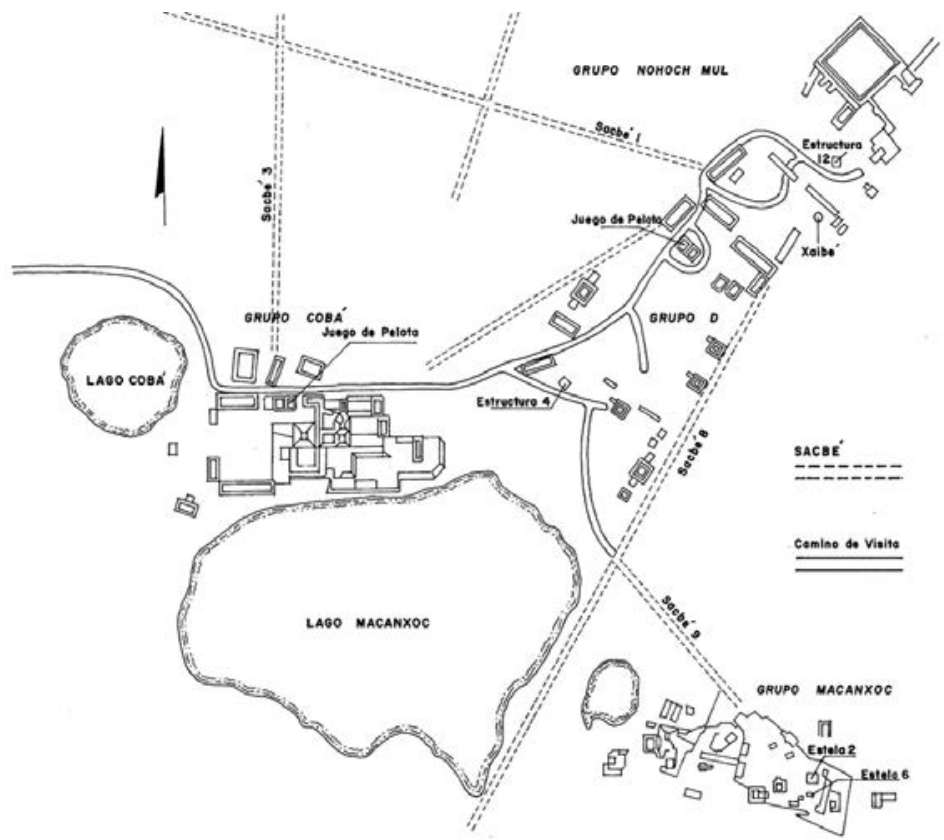

Figura 1. Plano de la zona nuclear de Cobá en el que se señalan los lugares donde se localizaron los objetos elaborados en concha (Dibujo de Julio Emilio Romero Martínez).

y Melgar, 2014: 3), lo que es un buen indicador de la existencia de relaciones interregionales.

Al lado opuesto del lago Macanxoc se localiza el grupo del mismo nombre; aquí se recuperaron, además de seis elementos de contextos secundarios, 136 objetos de concha distribuidos en tres ofrendas localizadas en las Estelas 2 y 6, y en el santuario de la Estructura 8 (Con, 2005; Con, Ochoa y Gómez, 2004; Con y Gómez, 2008: 127). La ofrenda de la Estela 6, que estaba compuesta por 250 elementos, incluidos objetos de concha, pedernal, pirita, obsidiana y piedra verde, está fechada para el Clásico Medio o Tardío (Con y Gómez, 2008: 127; Con, Ochoa y Gómez, 2004: 82, 83). Por el contrario, la presencia de cerámica Chen Mul en las ofrendas de la Estructura 8 y de la Estela 2 las han fechado como posclásicas (Con, Ochoa y Gómez, 2004: 65, Tabla 5; Con y Gómez, 2008: 123-124).

En el grupo Nohoch Mul se recuperaron 21 objetos de material malacológico, los cuales se localizaron en las ofrendas de la Estela 30 y de la Estructura 12, ambas fechadas para el Clásico Tardío (600-900 d.C.) (Con, 1998: 26-27). Finalmente, durante los trabajos de excavación y liberación de las estructuras del juego de pelota, el Conjunto Pinturas y el Xaibé, del Grupo D o Navarrete, se recuperaron seis objetos de concha que están fechados para el periodo Clásico (Con, 1998, 1999; Con, Ochoa y Gómez, 2004). 


\section{Identificación biológica de los objetos}

La identificación biológica de los materiales de concha recuperados se llevó a cabo con el fin de reconocer las especies a las que pertenecen las conchas y caracoles que sirvieron como materia prima para la elaboración de los objetos y, en consecuencia, identificar su procedencia. ${ }^{4}$ Como resultado de este estudio se reveló la presencia de dos clases del Phylum Mollusca, Gastropoda y Bivalvia, representadas por 10 géneros y 11 especies. Cuatro fragmentos no pudieron ser asociados a ninguna especie, género o familia biológica debido a su alto grado de deterioro. Del total de la colección, la clase Bivalvia cuenta con 235 elementos, en contraste con 57 objetos que fueron identificados dentro de la clase Gastropoda (Tabla 1).

\begin{tabular}{|c|c|c|c|}
\hline & Molusco & Provincia & Total \\
\hline \multirow[b]{9}{*}{ Clase Bivalvia } & Pintada mazatlanica & PANÁMICA & 26 \\
\hline & Isognomon sp & & 2 \\
\hline & Spondylus americanus & CARIBEÑA & 1 \\
\hline & Spondylus limbatus & PANÁMICA & 1 \\
\hline & Spondylus crassisquama & PANÁMICA & 193 \\
\hline & Chama coralloides & PANÁMICA & 9 \\
\hline & FAMILIA CARDIIDAE & & 1 \\
\hline & FAMILIA UNIONIDAE & & 1 \\
\hline & Psoronaias crocodilorum & $\begin{array}{l}\text { AFLUENTES DEL RÍO } \\
\text { USUMACINTA } \\
\end{array}$ & 1 \\
\hline \multirow[b]{5}{*}{ Clase Gastropoda } & Cittarium pica & CARIBEÑA & 2 \\
\hline & Lobatus costatus & CARIBEÑA & 36 \\
\hline & Lobatus gigas & CARIBEÑA & 17 \\
\hline & Neorapana muricata & PANÁMICA & 1 \\
\hline & Turbinella angulata & CARIBEÑA & 1 \\
\hline
\end{tabular}

Tabla 1. Moluscos identificados en la colección de objetos recuperados en las ofrendas de Cobá.

De las seis especies identificadas para la clase Bivalvia, Spondylus crassisquama, S. limbatus y Pinctada mazatlanica se distribuyen en el Océano Pacífico (provincia Panámica), y el resto pertenecen al Atlántico (provincia Caribeña). Además, se identificó la presencia de un ejemplar de la familia Cardiidae, sin poder definir género ni especie, y dos fragmentos del género Isognomon. Las especies de bival-

\footnotetext{
${ }^{4}$ La identificación se realizó con el apoyo de las biólogas Belém Zúñiga Arellano y Norma Valentín Maldonado. Para la identificación de las especies Lobatus costatus, L. gigas y Turbinella angulata se utilizó la técnica de fluorescencia de luz ultravioleta (uv), con el apoyo del doctor Emiliano Melgar Tísoc.
} 
vos más representativas en la colección son Pinctada mazatlanica, con 26 elementos, y Spondylus crassisquama, con 193.

Para la clase Gastropoda se identificaron cuatro especies, de las cuales sólo Neorapana muricata se distribuye en el Océano Pacífico, el resto son del Atlántico. Los elementos de Lobatus costatus son los más abundantes, teniendo un total de 36, seguidos de Lobatus gigas, con 17 elementos.

Dos ejemplares más se identificaron como bivalvos dulceacuícolas de la familia Unionidae; uno de ellos no pudo ser identificado por género y especie por encontrarse muy modificado, y el otro corresponde a un ejemplar de Psoronaias crocodilorum, especie que se distribuye en el río Usumacinta. ${ }^{5}$ Del total de la colección, 230 elementos pertenecen a especies del Océano Pacífico, mientras que 57 corresponde a ejemplares que habitan en el Atlántico (ver Tabla 1).

\section{Clasificación tipológica}

La tipología se basó en las clasificaciones de Lourdes Suárez (2002) y Adrián Velázquez (1999), de tal manera que es posible relacionar formas específicas para usos particulares, características que también pueden estar íntimamente relacionadas con la materia prima. Así, el mayor porcentaje de la colección (257 piezas) se clasificó según su función genérica en dos usos, ornamental y votivo; 27 elementos se clasificaron como evidencia productiva porque presentan modificaciones, aunque no tienen una forma específica y 12 fragmentos no se agruparon en ninguna categoría debido a que son resultado del deterioro de las piezas (Tabla 2).

En el uso ornamental se agruparon 236 ejemplares clasificados a su vez en cinco categorías según su función específica (cuentas, pendientes, incrustaciones, pectorales y orejeras) y 14 fragmentos que sabemos que corresponden a fragmentos de ornamentos, pero que no pueden ser clasificados en alguna categoría específica por no presentar los elementos que las definen. Del total de los objetos ornamentales, las incrustaciones destacan cuantitativa y cualitativamente ya que forman el $83.13 \%$ (207) de los objetos ornamentales. A diferencia de las cuentas, los pectorales y las orejeras que fueron elaborados exclusivamente en ejemplares del género Spondylus, las incrustaciones se elaboraron en Lobatus gigas, L. costatus, Spondylus crassisquama, Pinctada mazatlanica y Chama coralloides, y presentaron formas y tamaños diversos (ver Tabla 2). En esta categoría se agruparon objetos con y sin perforaciones que parecen haberse integrado a prendas cosidas a un soporte flexible, como tela, tal como Gallardo (2014) lo propuso para objetos de concha de Templo Mayor.

En el uso votivo se incluyeron aquellas piezas a las que no se les puede asignar otra función más allá de servir como elemento de ofrenda (Velázquez, 1999: 99); en éste se agruparon ocho elementos que conservaron su forma y características

$5<$ http://mussel-project.uwsp.edu/fmuotwaolcb/north_america.html $>$. 


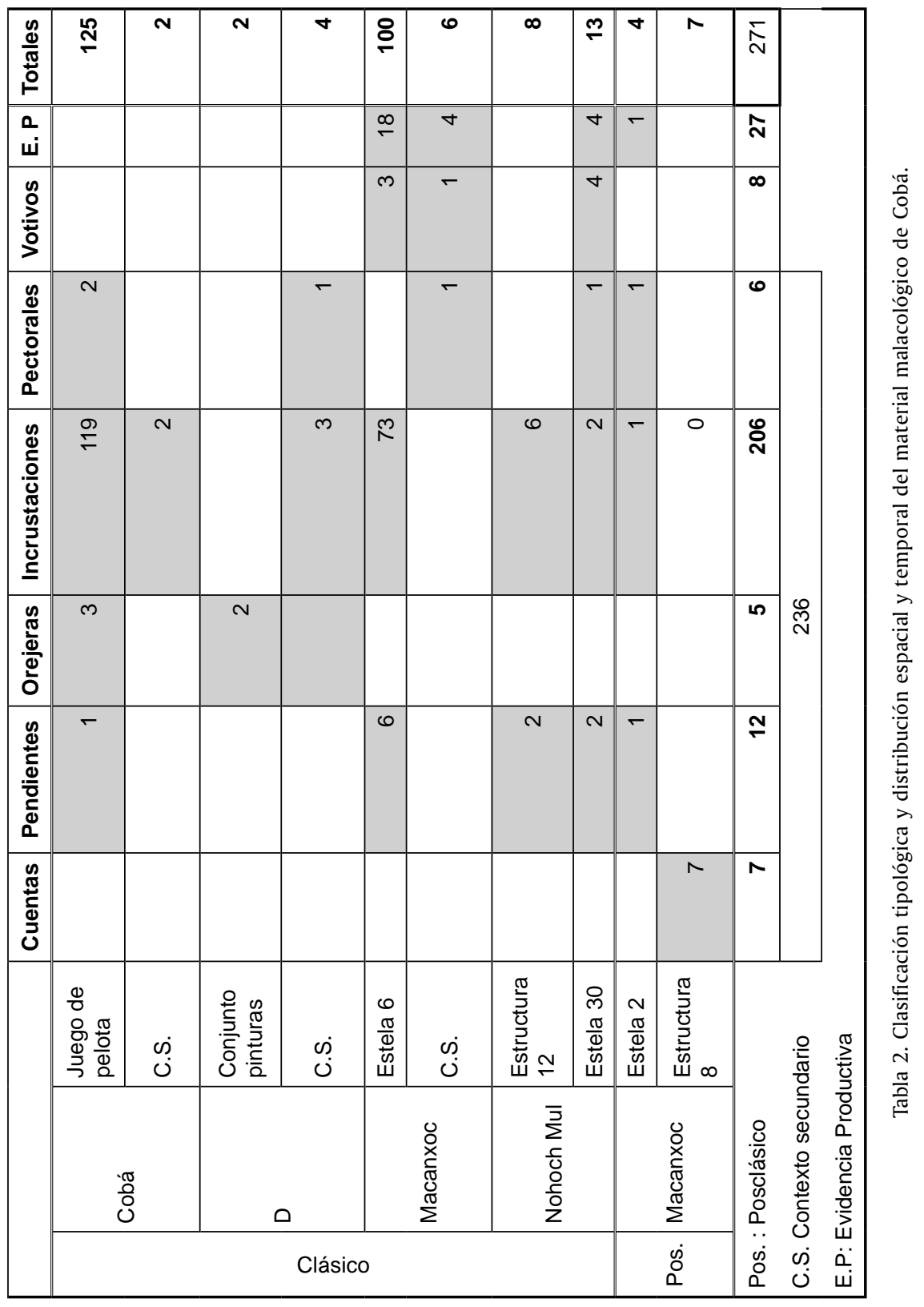


naturales por lo que se clasificaron según su clase biológica en gasterópodo trabajado y bivalvo trabajado (Figura 2, Tabla 2).

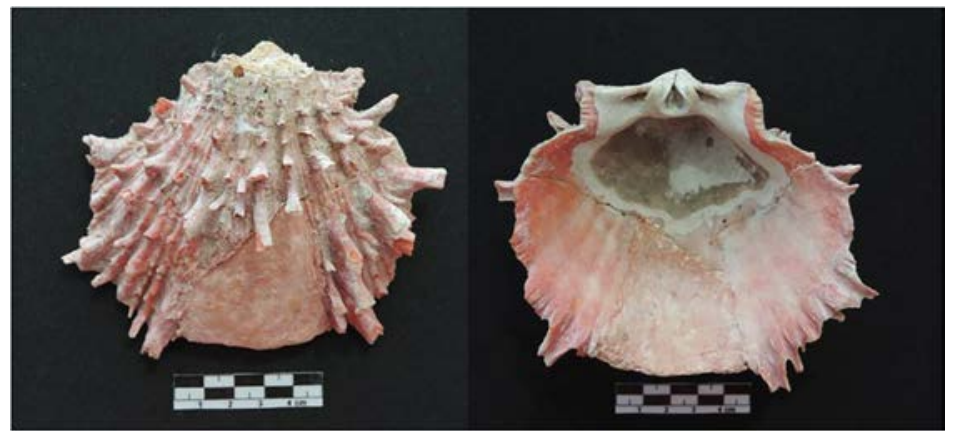

Figura 2. Valva votiva de Spondylus crassisquama recuperada en la Estructura 6 del grupo Macanxoc (Fotografías: E. A. Castillo Velasco).

\section{Distribución espacial de los objetos}

De las seis ofrendas, la del juego de pelota del grupo Cobá es la que concentra la mayor cantidad de objetos de concha (125), todos de uso ornamental, elaborados en Spondylus americanus, S. crassisquama, Chama coralloides y Lobatus costatus. Los pectorales llaman la atención pues en ellos se realizaron incisiones con las que se representaron personajes, muy probablemente asociados al juego de pelota, pero desafortunadamente no podemos conocer la escena completa porque en ambos casos se encuentran fragmentados. Elementos muy parecidos han sido ilustrados por Goldstein y Suárez (1997), de los cuales al menos uno ha sido identificado para tierras bajas guatemaltecas (Figura 3).

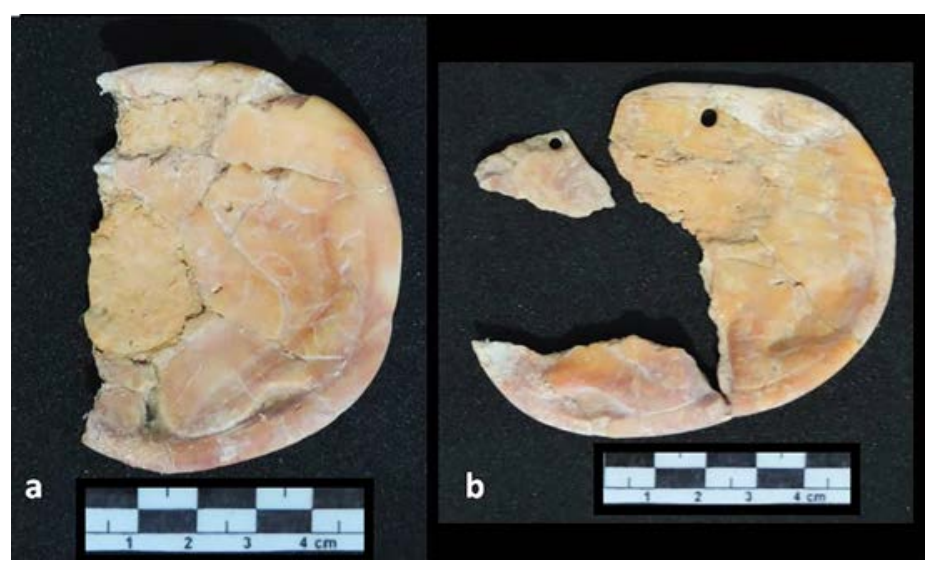

Figura 3. Pectorales incisos que formaban parte de la ofrenda del juego de pelota del grupo Cobá (Fotografías: E. A. Castillo Velasco). 
Las incrustaciones de esta ofrenda las podemos clasificar en dos grandes grupos; por un lado, 101 elementos que presentaron formas diversas geométricas y no geométricas que pudieron haber formado parte de un objeto complejo que integraba materiales de diferente tipo como puede ser una prenda, un mosaico o una máscara; aunque la mayoría de los objetos se encuentran fragmentados se puede observar la repetición de formas y una estandarización en el tamaño, principalmente en el espesor $(0.1 \mathrm{a} 0.2 \mathrm{~cm})$. También se hizo evidente que, en este caso, se buscó que las piezas fueran de color rojizo, ya que a pesar de que la mayoría se realizaron en Spondylus crassisquama hay seis elementos que fueron elaborados en otra especie pero con la misma coloración (cinco de Chama coralloides y uno sin identificar) (Figura 4).

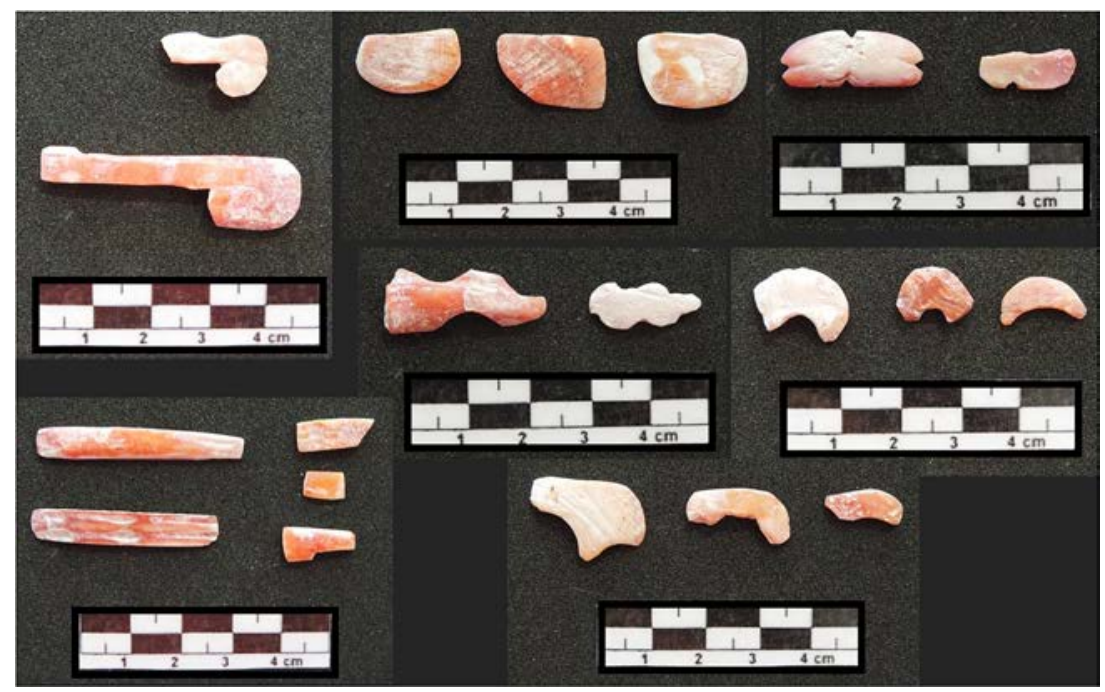

Figura 4. Algunos objetos clasificados como incrustaciones que se recuperaron en la ofrenda del juego de pelota del grupo Cobá y que pudieron haber estado adheridas, junto con piezas de otros materiales, a un soporte, formando un objeto complejo

(Fotografías: E. A. Castillo Velasco).

Cabe destacar que algunas formas representadas en este conjunto se asemejan a piezas reportadas en Calakmul; si bien hay similitud en las formas geométricas, son las no geométricas las que llaman la atención ya que son muy parecidas las incrustaciones de tipo voluta, colmillo, herradura y algunas irregulares (Colón, 2003: 95-97).

El segundo grupo estaría formado por 18 incrustaciones con formas particulares (zoomorfas, fitomorfas, geométricas y antropomorfas) que se presentan en dos tonalidades, rojo y blanco; las piezas de color rojizo corresponden con las especies Spondylus crassisquama, S. americanus y Chama sp. mientras que las de color blanco fueron elaboradas en Lobatus costatus (Figura 5). 


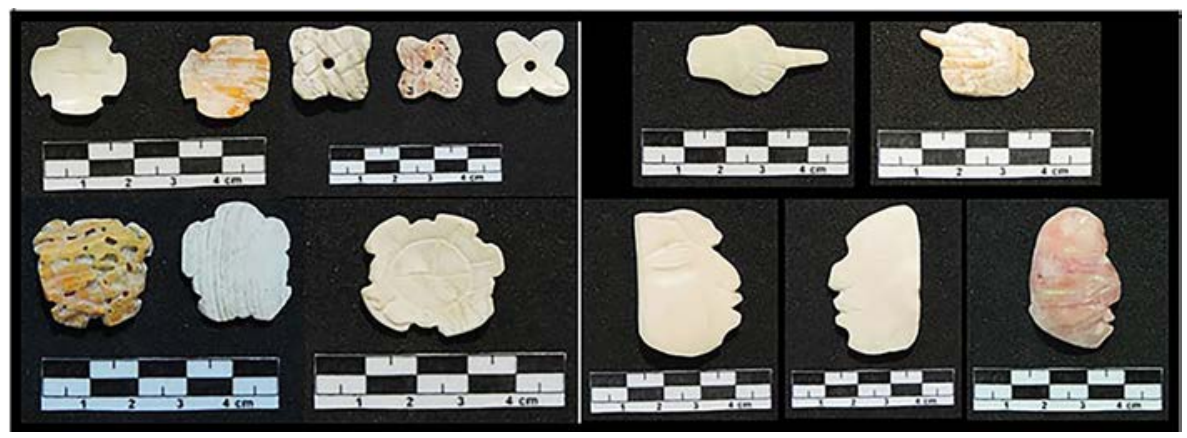

Figura 5. Incrustaciones con formas particulares de la ofrenda del juego de pelota del grupo Cobá (Fotografías: E. A. Castillo Velasco).

A la ofrenda del juego de pelota le siguió en términos cuantitativos aquella encontrada al pie de la Estela 6 dentro del grupo Macanxoc; en ella se recuperaron 126 objetos de concha, la mayoría de uso ornamental (93). Es en este contexto en donde se concentraron los objetos elaborados en Pinctada mazatlanica, con excepción de un fragmento de pendiente localizado en la ofrenda de la Estela 30 de Nohoch Mul y dos incrustaciones localizadas en contextos secundarios en el grupo Cobá y en el Xaibé, respectivamente.

Nueve de las piezas de Pinctada mazatlanica de esta ofrenda corresponden a diez incrustaciones de forma trapezoidal con un borde semicircular, algunas presentan perforaciones y todas están incisas en la cara ventral con diseños que representan personajes y glifos; sus características sugieren que se trata de piezas de un objeto compuesto por diferentes materiales y por eso, al sólo tener estas piezas, no es posible acomodarlas en un diseño especifico ${ }^{6}$ (Figura 6).

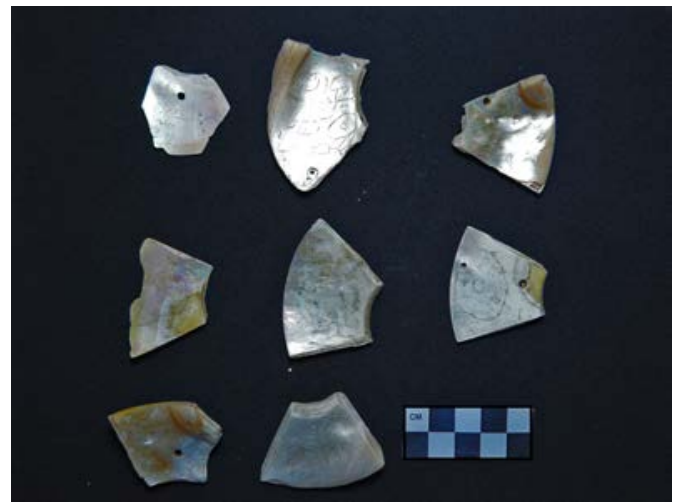

Figura 6. Incrustaciones de Pinctada mazatlanica que muy probablemente formaban parte de un objeto compuesto por diferentes materiales y que se ofrendó al pie de la Estela 6 .

Es evidente la intencionalidad de las formas y el aprovechamiento de la valva utilizada (Fotografía: E. A. Castillo Velasco).

${ }^{6}$ Lourdes Gallardo, comunicación personal, 2016. 
Además de dichas incrustaciones, la ofrenda contenía 19 objetos y 46 fragmentos de Spondylus crassisquama, que pudieron formar parte de un conjunto, quizá junto con las piezas de Pinctada mazatlanica; la mayoría de estos objetos (51) se clasificaron como incrustaciones a pesar de que algunos presentan una o más perforaciones, y seis se clasificaron como pendientes (Figura 7).

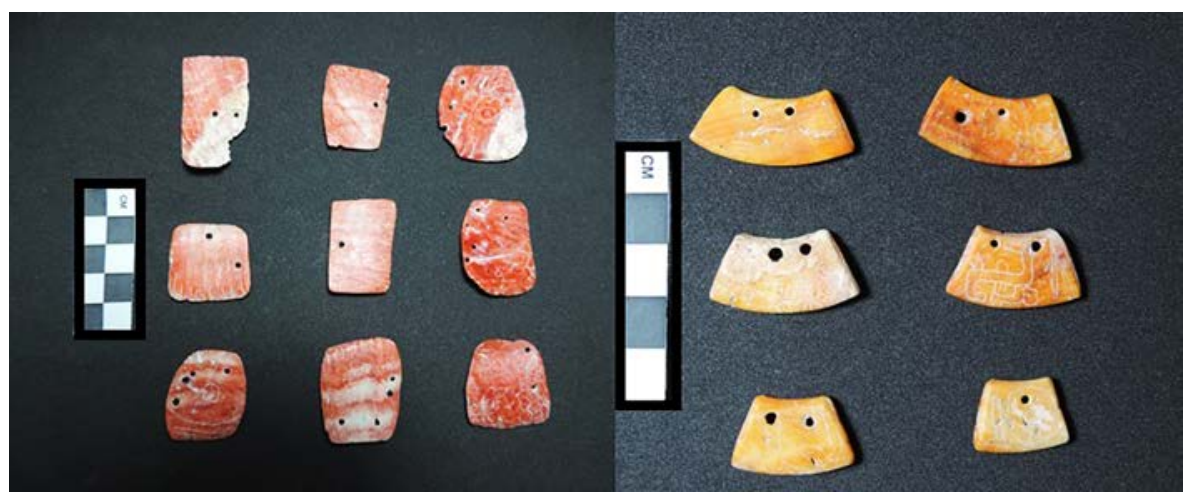

Figura 7. Objetos de Spondylus crassisquama de la ofrenda de la Estela 6 (Fotografías: E. A. Castillo Velasco).

En estos objetos se puede observar la estandarización en el color, pero aunque las formas tienden a ser similares no se observa un patrón definido con excepción de los pendientes. Al igual que las incrustaciones trapezoidales de Pinctada mazatlanica presentan incisiones que dan forma a glifos o personajes, los cuales se han definido como la representación de algunas deidades como el Dios Viejo (Figura 8). ${ }^{7}$

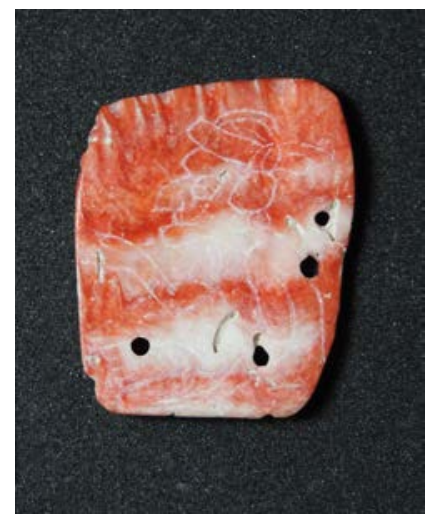

Figura 8. Incrustación de Spondylus crassisquama en la que se aprecia el diseño de un personaje que podría representar un dios viejo en posición sedente

(Fotografía: E. A. Castillo Velasco).

\footnotetext{
${ }^{7}$ María José Con, comunicación personal, 2011.
} 
Finalmente, la ofrenda también contenía 12 incrustaciones de Lobatus costatus, seis circulares y seis geométricas fragmentadas; estas últimas son semejantes a las de Spondylus crassisquama y al igual que aquéllas, presentan incisiones sobre una de sus caras (Figura 9).

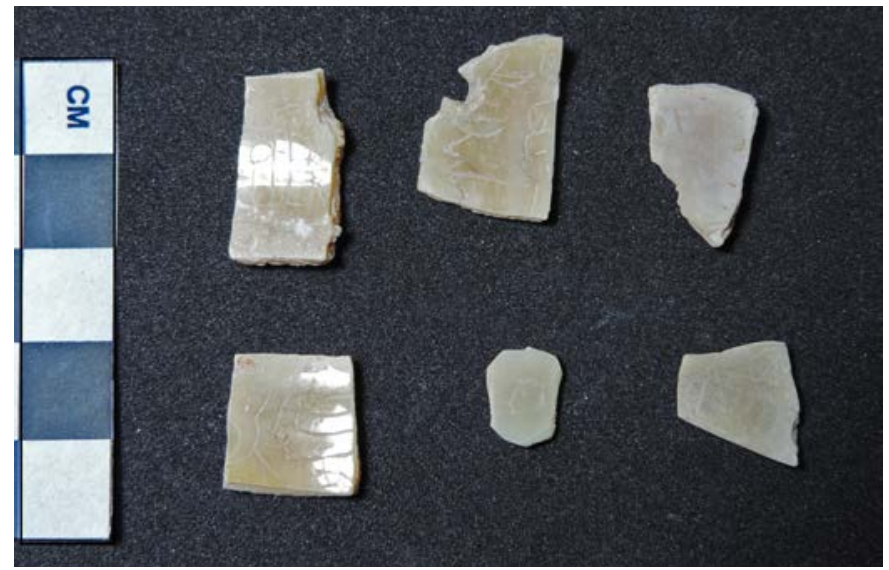

Figura 9. Fragmentos de incrustaciones de Lobatus costatus con diseños incisos (Fotografía: E. A. Castillo Velasco).

Por otro lado, las ofrendas de la Estela 30 y la Estructura 12, ambas del Nohoch Mul, fechadas para el Clásico Tardío, presentan diferencias tanto cuantitativas como cualitativas con respecto a las del Clásico Temprano (juego de pelota y Estela 6). Por un lado, los ocho objetos de concha recuperados en la Estructura 12 corresponden a incrustaciones y pendientes elaboradas en Lobatus gigas y su acabado es mucho más sencillo que los objetos de las otras ofrendas (Figura 10).

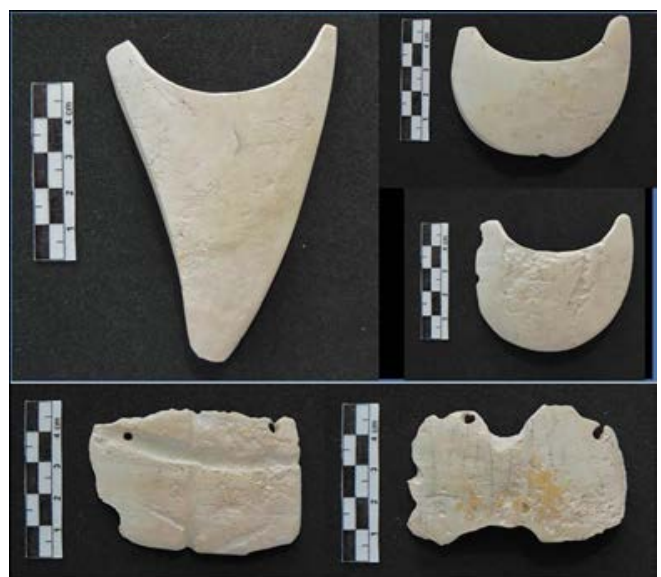

Figura 10. Objetos de Lobatus gigas fechados para el Clásico Tardío y que se recuperaron en la ofrenda de la Estructura 12 (Fotografías: E. A. Castillo Velasco). 
La ofrenda de la Estela 30 estaba compuesta por trece objetos de concha, entre ellos los cuatro ejemplares de Lobatus gigas, clasificados como votivos, así como un pendiente fragmentado de Pinctada mazatlanica, con incisiones y que podría haber representado un perfil antropomorfo (Figura 11).

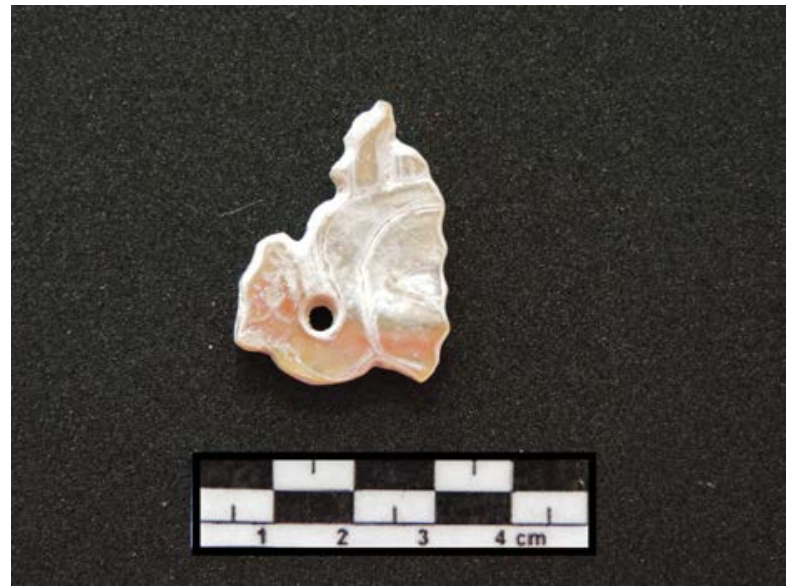

Figura 11. Pendiente de Pinctada mazatlanica que podría representar un perfil antropomorfo, fechado para el Clásico Tardío y recuperado en la ofrenda de la Estela 30 (Fotografía: E. A. Castillo Velasco).

Finalmente, las ofrendas del Posclásico, ambas de Macanxoc, no sólo son mucho más pequeñas en términos cuantitativos, sino que, además, el tipo de objetos utilizados contrasta con los objetos clásicos. La ofrenda del santuario de la Estructura 8 destaca por la presencia de cuentas, objetos que si bien son comunes temporal y espacialmente en la región, en las ofrendas estudiadas del Clásico no fueron utilizadas, ${ }^{8}$ aunque sí comparten la materia prima, ya que fueron elaboradas tres en el género Spondylus (dos en S. crassisquama y uno en $S$. limbatus) y tres en Chama coralloides.

Y en el caso de la ofrenda de la Estela 2, la diferencia radica en tres aspectos. El primero es la presencia de un pendiente semicompleto elaborado en un ejemplar de la familia Unionidae, que no estuvo presente en las ofrendas del Clásico, aunque sí apareció una incrustación elaborada en un ejemplar de Psoronaias crocodilorum (Figura 12) en el escombro de la escalinata jeroglífica del grupo Cobá, el cual estaría fechado para el Clásico.

${ }^{8}$ Cabe señalar que en el artículo de Con y Esparza, "Recovered History: Stela 11 of Coba", se reporta que en la parte inferior de la Estela 11 del grupo Cobá se encontró una cista circular que contenía una ofrenda del Clásico, compuesta, entre otros materiales, por siete valvas de Spondylus y siete cuentas de concha (Con y Esparza, 2016: 4). Sin embargo, este material no estuvo disponible al momento del análisis llevado a cabo por el presente proyecto. 


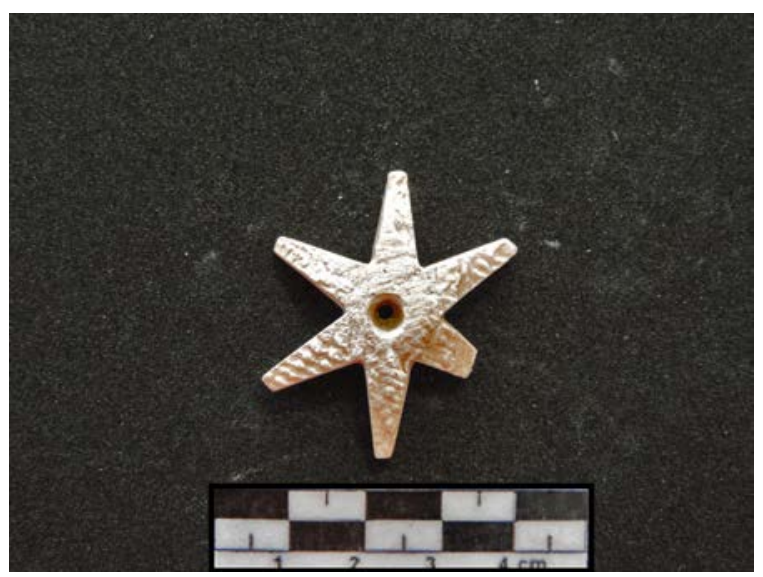

Figura12. Incrustación de Psoronaias crocodilorum, especie de la familia Unionidae. El objeto se encontró en el escombro de la escalinata jeroglífica del grupo Cobá (Fotografía: E. A. Castillo Velasco).

La segunda diferencia está en que, aunque las especies e incluso las formas generales coinciden, no lo hacen las características particulares; por ejemplo, entre los objetos se encuentra una mitad de pectoral de Spondylus crassisquama que, aunque presenta ambas superficies desgastadas y perforación cónica, igual que en las piezas del Clásico, le fue dejada una de las espinas. Además, fue ofrendada una sección de costilla de la misma especie, que conserva sus espinas y a la que no se le pudo identificar una función específica; este tipo de elemento, clasificado como evidencia productiva, no aparece en las ofrendas del Clásico (Figura 13).

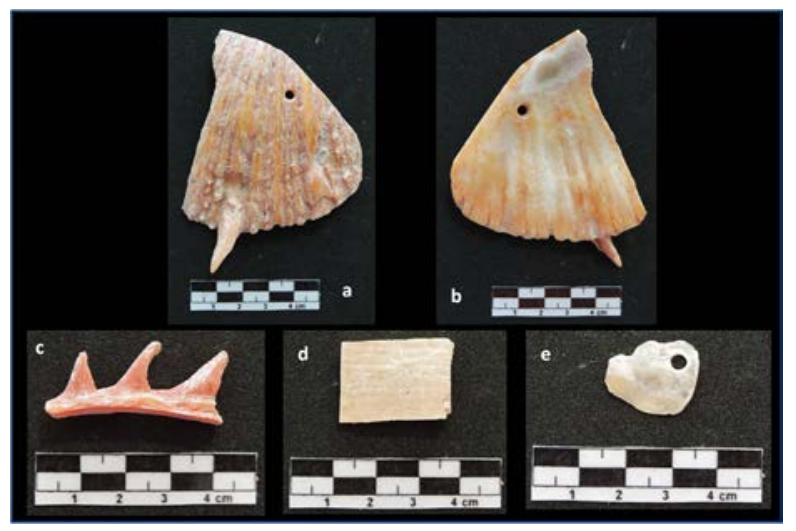

Figura 13. Objetos ofrendados durante el Posclásico en la Estela 2. Arriba se observa la mitad de un pectoral de Spondylus crassisquama desgastado tanto en la cara dorsal (a) como en la cara ventral (b); abajo se aprecian una sección de costilla con espinas de S. crassisquama

(c), una incrustación rectangular de Lobatus costatus (d) y un pendiente semicompleto de una especie de la familia Unionidae (e) (Fotografías: E. A. Castillo Velasco). 


\section{Análisis de las huellas de manufactura}

Para llevar a cabo el análisis de las huellas de manufactura se seleccionó una muestra que tuvo en cuenta el grado de deterioro, el número y tipo de modificaciones, la especie, la forma, así como su contexto. De esta manera, la muestra quedó compuesta por 37 objetos que representaban a las seis ofrendas y en los cuales se podían apreciar los acabados, las perforaciones, las incisiones y los cortes (Tabla 3).

Las huellas de manufactura de los objetos arqueológicos fueron comparadas con huellas producidas experimentalmente dentro del taller de concha del PTMOсмP, siguiendo los criterios establecidos por dicho proyecto para llevar el control de los experimentos, los tiempos y los procedimientos utilizados (Velázquez, 2012: 230).

Las huellas, tanto arqueológicas como experimentales, se observaron microscópicamente a través de su réplica en polímeros y utilizando un microscopio electrónico de barrido ${ }^{9}$ (МЕв). La observación se realizó siguiendo siempre los mismos parámetros para que las imágenes obtenidas fueran susceptibles de comparación; todas las muestras se observaron en el modo de alto vacío, con señal de electrones secundarios (SEI), un voltaje de $20 \mathrm{kv}$, un tamaño de haz de 40 y a $10 \mathrm{~mm}$ de distancia. El análisis reveló el uso de arenisca y pedernal para desgastar las superficies (ver Tabla 3). En la superficie de 17 objetos, tanto del Clásico como del Posclásico, de Spondylus crassisquama, Chama coralloides, Lobatus gigas, L. costatus y Pinctada mazatlanica, se observaron a 600x gran cantidad de líneas finas de una micra y bandas de cinco micras, que se distribuyen de forma recta, continuas y paralelas consistentes con desgastes hechos con pedernal (Figura 14).

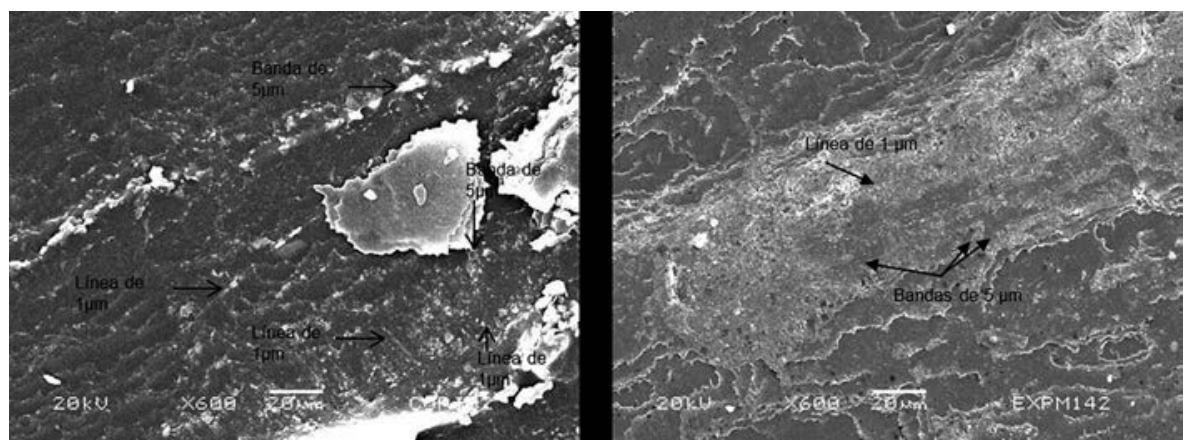

Figura 14. Huellas de desgaste en un objeto de Cobá de la especie Pinctada mazatlanica (izquierda) y huellas producidas experimentalmente al desgastar la superficie de una valva de P. mazatlanica con pedernal (Imágenes cortesía del ртмосмP).

${ }^{9}$ El microscopio utilizado pertenece a la Subdirección de Laboratorios y Apoyo Académico del INAH, por lo que se agradece a Gerardo Villa la ayuda prestada, y quien se desempeñó como encargado del Laboratorio de Microscopía en dicho centro durante el periodo de la investigación. 


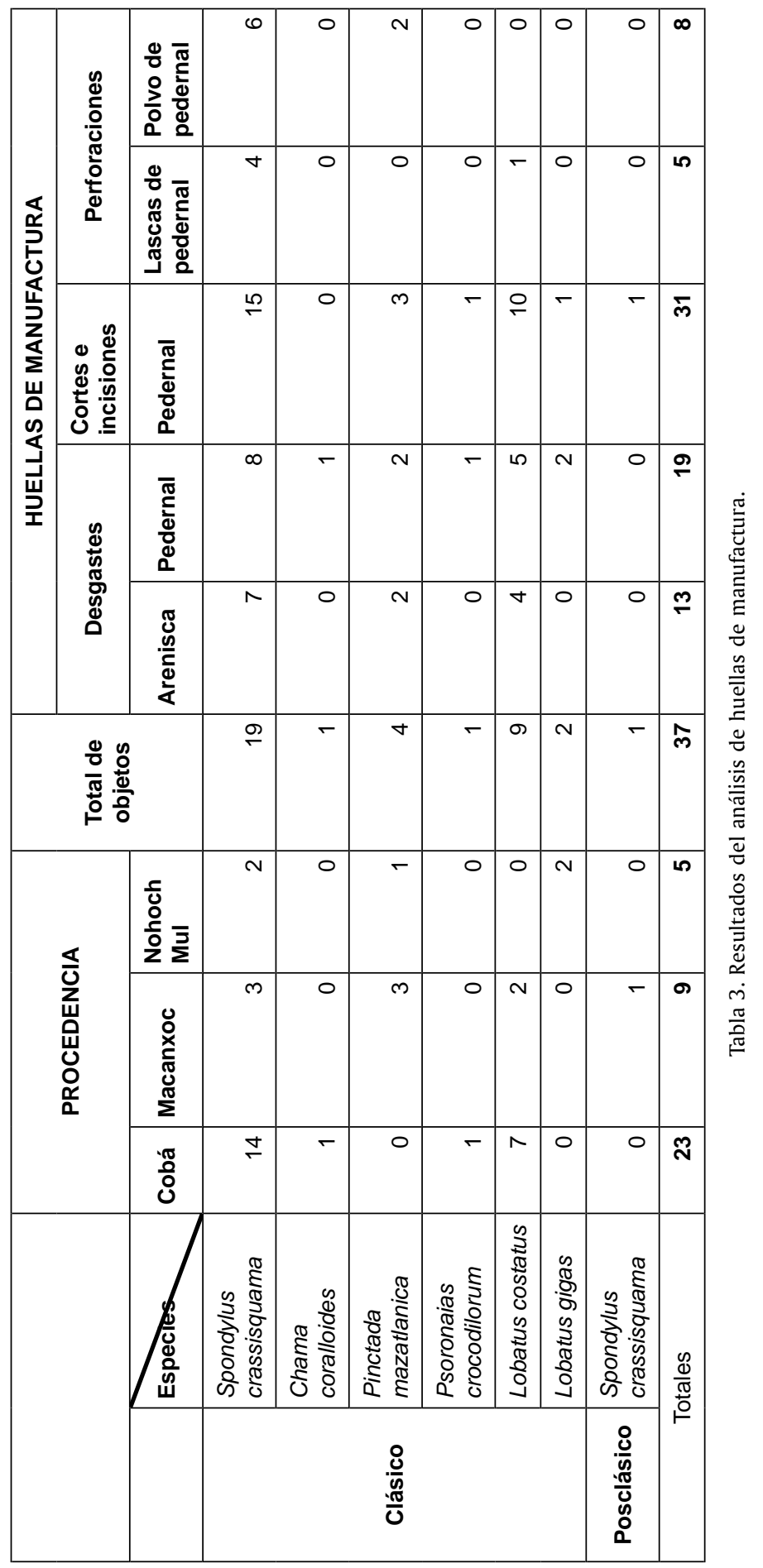


Por otro lado, en nueve objetos de Spondylus crassisquama, Lobatus costatus y Pinctada mazatlanica, todos del Clásico, se observaron bandas de 3.5 y 5 micras, que se entretejen rompiendo la continuidad de las bandas, y aunque también presentan líneas finas, la apariencia de la superficie es más gruesa que la dejada por el pedernal (Figura 15).
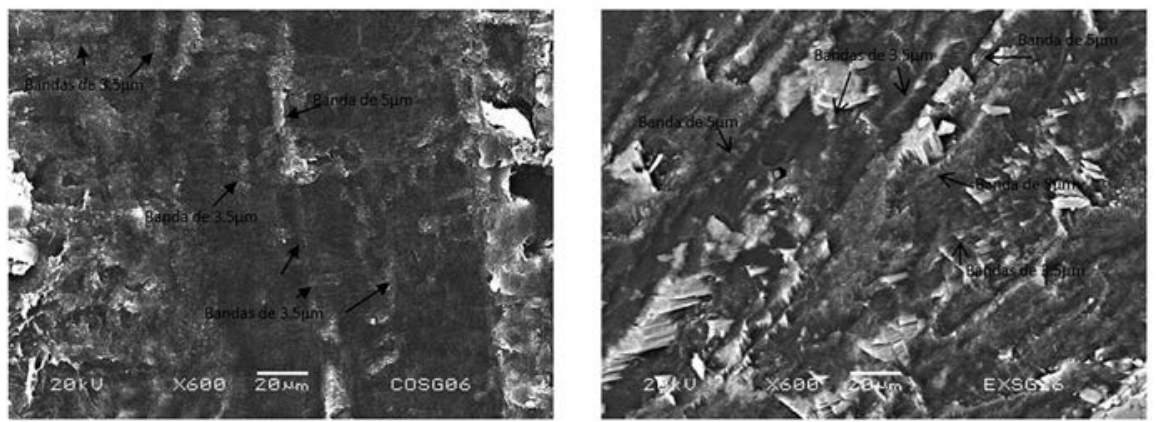

Figura 15. Huellas de desgaste en un objeto arqueológico de Lobatus costatus, recuperado en Cobá (Izquierda) y huellas producidas experimentalmente al desgastar la superficie de un fragmento de L. gigas con arenisca (Derecha) (Imágenes cortesía del ртмосмP).

Los cortes observados en los bordes de las piezas arqueológicas presentaron, en todos los casos, una textura rugosa en la que se distribuyen, de forma paralela y continua, una gran cantidad de líneas finas rectas de alrededor de una micra y que pueden llegar a formar bandas; características consistentes con las huellas que deja el uso de lascas de pedernal (ver Tabla 3, Figura 16).

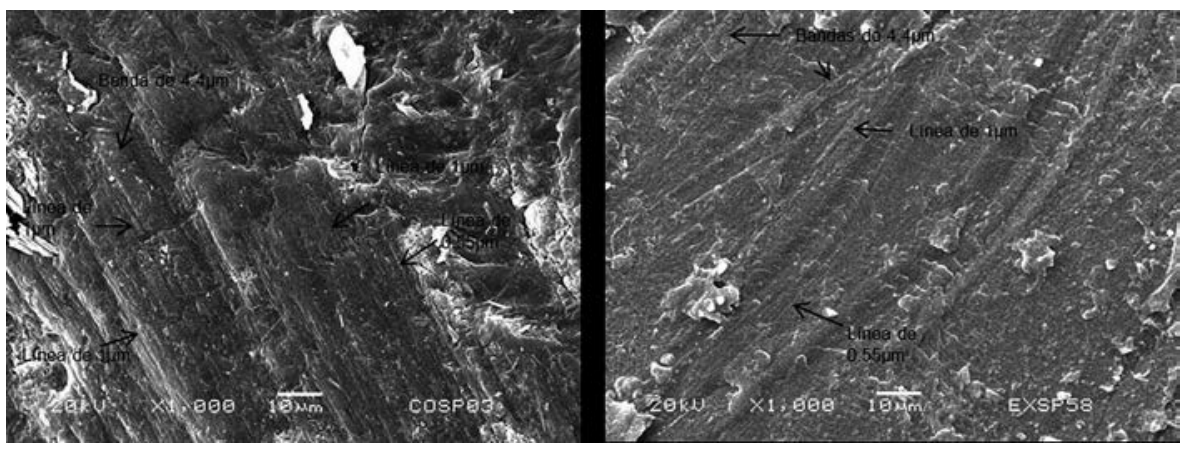

Figura 16. Huellas presentes en el borde de un objeto recuperado en Cobá de Spondylus crassisquama (Izquierda) y huellas producidas experimentalmente al cortar una superficie de S. crassisquama con lascas de pedernal (Derecha) (Imágenes cortesía del PтмосмP).

Las perforaciones observadas con мEB también mostraron el uso de pedernal y fue posible identificar su uso a través de dos procedimientos distintos (ver Tabla 3 ). En cuatro de las 12 perforaciones analizadas, se observaron bandas paralelas 
de cuatro micras sobre una superficie rugosa, consistentes con las huellas que se obtienen al perforar utilizando lascas o perforadores de pedernal. Los objetos que presentaron estas huellas corresponden con dos incrustaciones recuperadas en la ofrenda del juego de pelota del grupo Cobá y dos pendientes de la ofrenda de la Estela 6 de Macanxoc (Figura 17).

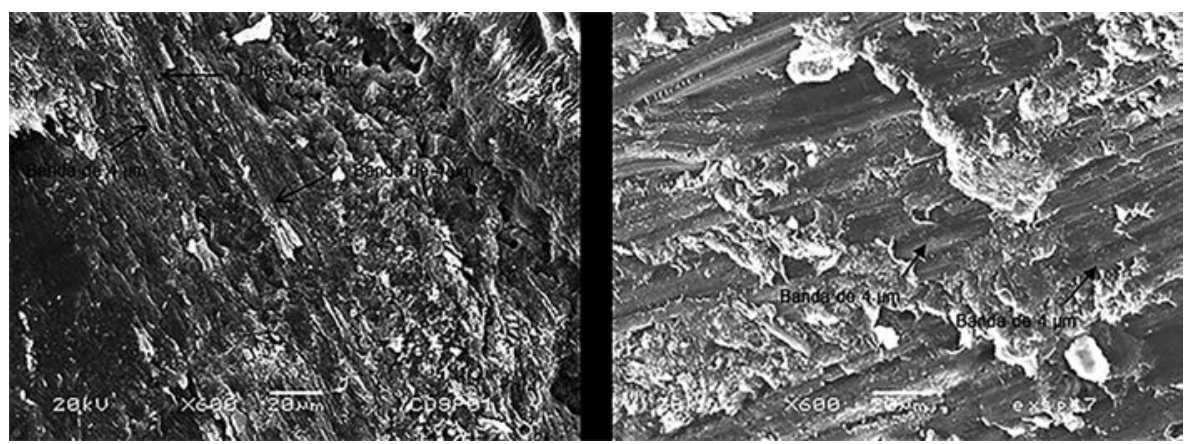

Figura 17. Huellas presentes en la perforación de un objeto arqueológico de Spondylus crassisquama recuperado en Cobá (Izquierda) y huellas producidas experimentalmente al perforar una superficie de S. crassisquama con lascas de pedernal (Imágenes cortesía del PтмосмP).

Las ocho perforaciones restantes presentaron líneas muy finas, de una micra o menos, y un relieve suavizado; características observadas al perforar utilizando polvo de pedernal (Figura 18).

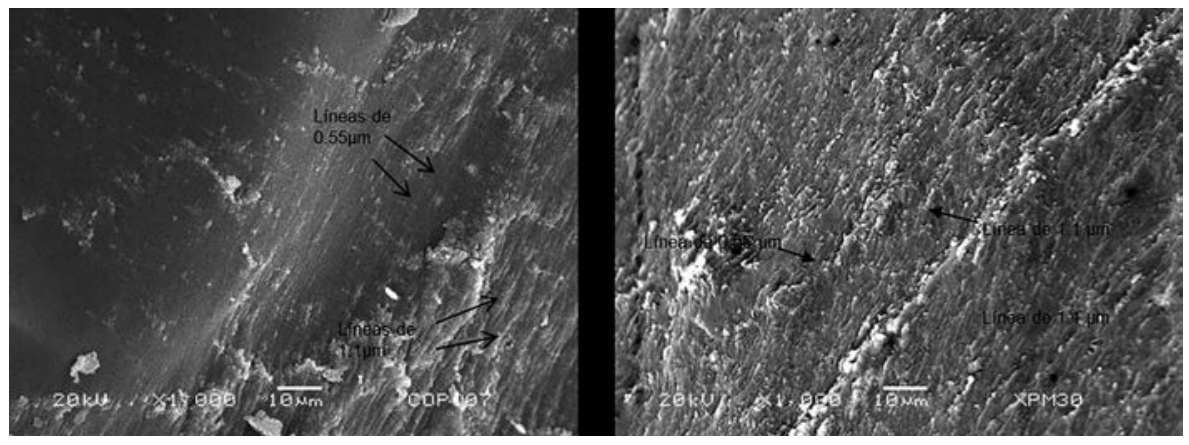

Figura 18. Huellas presentes en la perforación de un objeto de Pinctada mazatlanica recuperado en la ofrenda de la Estela 6 (Izquierda) y huellas producidas experimentalmente al perforar una superficie de P. mazatlanica con polvo de pedernal (Derecha)

(Imágenes cortesía del PTMOсMP).

\section{Resultados y consideraciones finales}

Al revisar la información resultante del análisis de la colección se hizo evidente que los objetos de concha fueron elaborados tanto en especies que podríamos 
llamar locales como en especies foráneas. De las especies locales destaca la preferencia en el uso de ejemplares del género Lobatus, principalmente de L. costatus, un caracol que ha sido reportado con mayor abundancia para las costas norte y oeste de la península de Yucatán, sin descartar su presencia en la costa este de Quintana Roo (Andrews, 1969: 3, 37; Vokes y Vokes, 1983). Las 11 especies identificadas, con excepción de Spondylus limbatus, y el ejemplar de la familia Cardiidae, se encuentran en contextos del Clásico, pero sólo cuatro y el ejemplar de la familia Unionidae se encontraron también en contextos del Posclásico.

Es interesante resaltar que para el Posclásico no sólo hay una disminución en la cantidad de especies presentes sino también en la cantidad de elementos para cada especie identificada; así, de las cuatro especies presentes para este periodo dos son del Océano Pacifico (Spondylus crassisquama y Chama coralloides) y cuentan con la mayor cantidad de elementos, siete contra dos objetos del Atlántico.

La presencia de especies foráneas apoya las hipótesis sobre las relaciones interregionales; por un lado, las especies de la provincia Panámica debieron haber llegado desde la costa del Pacífico siguiendo las rutas establecidas para cada época siempre acompañadas de otros productos, mientras que la presencia de la especie Psoronaias crocodilorum evidencia la relación con la región del Usumacinta.

Con la clasificación tipológica se hizo evidente que para el Clásico se utilizó un mayor número de objetos. Es de resaltar que los elementos votivos sólo se utilizaron en las ofrendas del Clásico; esto junto con la gran cantidad de incrustaciones y los diseños incisos presentes en los objetos sugieren que cada elemento fue seleccionado con un propósito específico en el marco del diseño de la ofrenda. Si bien la clasificación tipológica de los objetos de concha ha permitido suponer que se trata de piezas que formaban parte de objetos complejos, el análisis integral de los materiales permitiría conocer qué tipo de objetos se ofrendaron y qué otros materiales se utilizaron en su elaboración.

Las incisiones que son parte del diseño de personajes y posibles caracteres de escritura sugieren que la producción de estos objetos fue realizada por artesanos de la élite, tal como se propone para los objetos de la Estructura II de Calakmul (Melgar y Domínguez, 2014) y como lo documenta Inomata (2007) para Aguateca, Guatemala, tomando en cuenta que para la elaboración no sólo se requirió de las habilidades sobre la producción, también fue necesario el conocimiento de la escritura que junto con el bagaje histórico, mitológico y astronómico permitieron legitimar y enaltecer a las élites mayas.

Las evidencias productivas permiten inferir la elaboración de los objetos dentro de la zona nuclear de Cobá debido a que en ellos están representadas cuatro de las especies identificadas en objetos ornamentales, tanto del Pacífico como del Caribe; su hallazgo dentro de las ofrendas de las Estelas 6 y 30 les denotan un valor especial como parece haber ocurrido en Tikal, donde Moholy-Nagy sugiere que los desechos de manufactura, e incluso la materia prima de materiales exclusivos de la élite como jade, hematita, obsidiana, pedernal y Spondylus, fueron colocados dentro de los "depósitos especiales" como un tipo de ofrenda, ya que 
observa diferencias entre estas acumulaciones y aquellas asociadas a espacios domésticos (chultunes) (Moholy-Nagy, 1997: 301, 302).

Al ser notorias las diferencias entre los tipos de objetos utilizados para cada ofrenda, y más aún las diferencias morfológicas y funcionales asociadas temporalmente, el análisis de las huellas de manufactura despejaría las incógnitas sobre sus características productivas (procesos y herramientas utilizados en la elaboración) y con ello se obtendría información que permitiera sustentar la hipótesis de una producción local exclusiva de la manufactura de objetos de uso ritual y la presencia de objetos que ligaran a la élite de Cobá con otros sitios a partir de la asociación de características morfofuncionales y tecnológicas.

Sin embargo, aunque el análisis de las huellas de manufactura refiere el uso de dos materiales diferentes para desgastar las superficies, el uso de pedernal para perforar y cortar, sin importar el instrumento de desgaste, la especie y/o la ofrenda, sugiere que los objetos fueron elaborados con fines específicos dando prioridad a las características morfológicas sobre la estandarización tecnológica (ver Tabla 3).

El uso de dos herramientas diferentes de desgaste podría explicarse siguiendo las propuestas de Navarrete, Con y Martínez (1979) y Benavides (1981), que sugieren que uno de los factores que permitió la consolidación de la ciudad fue la organización de grupos productores de la región que habitaban en asentamientos colindantes a Cobá en la costa y tierra adentro durante el Preclásico Tardío y Clásico Temprano; de esta manera cada grupo llevaría sus tradiciones, pero respondiendo a las necesidades impuestas por la élite de Cobá. Si bien la presencia de varios grupos productores favorecería una mayor variedad tecnológica, dado que el material estudiado proviene de contextos de élite, ello estaría limitando tal diversidad.

Si partimos de la idea previa sobre que las diferencias morfológicas entre los objetos de cada ofrenda evidencian que fueron elaborados con un objetivo específico, enmarcado en el diseño de la ofrenda, al compartir características tecnológicas se infiere que los objetos fueron realizados por un grupo productivo conformado por artesanos, probablemente con diferentes tradiciones, y dado que se requería del conocimiento histórico-cultural además del productivo es posible suponer que su elaboración formaba parte de una producción adjunta dedicada a fabricar bienes que respondieran a las necesidades de control político (Brumfiel y Earle, 1990: 5; Costin, 2007: 152). Aunque los resultados obtenidos llevan a pensar que los objetos se elaboraron en Cobá, será relevante hacer una revisión del total de materiales recuperados, con el fin de encontrar las evidencias que sustenten la presencia de los materiales foráneos que se utilizaron en la elaboración de objetos de concha.

Las incrustaciones con forma de perfiles humanos y manos son un elemento que permite conocer los lazos interregionales al estar presentes en sitios que podrían marcar el corredor cultural y comercial entre el Petén y la península de Yucatán. El análisis de sus huellas de manufactura reveló el uso de pedernal 
para desgastar y cortar, a diferencia de los perfiles antropomorfos y las manos de Xcaret y Xcambó, ya que en el caso de los objetos de Xcaret, Páez (2017) reporta el uso de roca caliza para desgastar, mientras que el análisis realizado por Velázquez y Melgar (2014), refiere que el perfil antropomorfo de Xcambó fue desgastado con arenisca. A pesar de esta diferencia, el uso de arenisca parece ser un indicador de una tradición regional porque su uso también ha sido reportado para otros sitios, lo que toma mayor relevancia debido a que es una roca que, de acuerdo con el mapa digital del Instituto Nacional de Estadística, Geografía e Informática (2019) y el Mapa Fisiográfico-Geomorfológico de la República de Guatemala (Ministerio de Agricultura, Ganadería y Alimentación, 2001), se distribuye en el área maya central y no en la península de Yucatán. Debido a que, como se ha hecho notar, Cobá presenta una conexión importante con asentamientos del Petén y Belice, es de suponer que la arenisca también llegara desde esta región.

Aunque en principio se esperaba que los perfiles humanos y las manos tuvieran características tecnológicas diferentes al resto de los objetos, pensando en la posible importación de los mismos, las características tecnológicas compartidas con el resto de los objetos de Cobá y la diferencia en la manufactura entre los perfiles antropomorfos y las incrustaciones en forma de mano de Cobá y sus pares de Xcambó y Xcaret permiten discutir sobre manufacturas locales que responden a una misma tradición.

Lo mismo pudo ocurrir con las incrustaciones de Calakmul, aunque en este caso, en la colección estudiada por Colón (2003), éste encuentra que algunas piezas fueron desgastadas también con arenisca; a su vez encuentra que los materiales de Calakmul comparten un parecido en cuanto a tipos, especies, contextos y temporalidad con Tikal y sugiere, por la diversidad de huellas de manufactura identificadas en su análisis, que pudieron ser importados aunque la presencia de algunos objetos en proceso y desechos de trabajo también la hicieron pensar en una producción local (Colón, 2003: 141).

$\mathrm{Si}$ bien es posible que en cada sitio se manufacturaran los objetos con base en una misma tradición cultural, la presencia de objetos similares en sitios diferentes distribuidos desde el área maya central hasta el norte de la península de Yucatán también hacen pensar en la posibilidad de que existieran grupos productores que abastecían de objetos específicos a la región. Al igual que con los análisis de cerámica (Robles, 1990) y lítica (Braswell, 1997), o con las propuestas para la llegada de bienes a Calakmul (Melgar y Domínguez, 2017: 114-115) para identificar posibles rutas de comercio, el análisis de los objetos de concha desde el punto de vista tecnológico permitiría reconocer elementos comunes que relacionen a los sitios que formaban parte del corredor cultural entre el Peten y la península de Yucatán durante el Clásico.

Por otro lado, a nivel intrasitio, si partimos de la idea de que la manufactura siempre se dará en el marco de un contexto específico que incluye el espacio y los aspectos sociopolíticos e ideológicos (Costin, 2007: 150), la comparación de las características morfofuncionales y tecnológicas de los objetos de las ofrendas 
de Cobá y aquellos recuperados en las zonas habitacionales permitiría inferir sobre el acceso diferencial de los recursos, el control y distribución de bienes y la diversidad en estilos tecnológicos tomando en cuenta que la ciudad habría integrado a diferentes grupos productores.

Finalmente, resulta interesante que los cambios sociales y políticos en los que estuvo inmerso Cobá entre el Clásico Tardío y Posclásico se reflejen en la disminución de las especies y objetos elaborados y utilizados en las ofrendas, aunque la continuidad en los procesos de manufactura sugiere que, al ser desplazado como centro colector y redistribuidor de bienes y al cambiar las rutas de comercio, la élite de Cobá intentó mantenerse a pesar de que los recursos a su alcance se vieron limitados.

\section{Agradecimientos}

A María José Con por otorgar todas las facilidades para la revisión de la colección, por sus comentarios y observaciones. A Adrián Velázquez Castro por dirigir y apoyar esta investigación, pero sobre todo por su confianza y por abrirme las puertas del proyecto тмосмр. A Belem Zúñiga y Norma Valentín por el tiempo brindado para la identificación biológica de las especies. A Emiliano Melgar por su apoyo para la realización de la técnica de fluorescencia de luz uv y por los comentarios al texto. Al Laboratorio de Microscopía de la Subdirección de Apoyo Académico del INAH y, finalmente, a Lynneth Lowe y Octavio Esparza, quienes se tomaron el tiempo para revisar este documento y lo enriquecieron con sus observaciones.

\section{Bibliografía}

Alonso, Alejandra, Adrián Velázquez, Kam Manahan, Belem Zúñiga, Norma Valentín y Traci Ardren

2013 "Análisis de las técnicas de manufactura de los objetos de concha de Xuenkal, Yucatán”, Técnicas analíticas aplicadas a la caracterización y producción de materiales arqueológicos en el área maya, pp. 109-134, Adrián Velázquez y Lynneth S. Lowe (eds.). México: Universidad Nacional Autónoma de México, Instituto de Investigaciones Filológicas, Centro de Estudios Mayas (Serie Testimonios y Materiales Arqueológicos para el Estudio de la Cultura Maya, 4).

Andrews IV, Wyllys

1969 The Archaeological Use and Distribution of Mollusca in the Maya Lowlands. New Orleans: Middle American Research Institute, Tulane University (National Geographic Society, Tulane University Program of Research in Yucatan, 34).

Arnauld, Charlotte

1990 "El comercio clásico de la obsidiana", Latin American Antiquity, 1 (4): 347-367. 
Benavides Castillo, Antonio

1976 “Cobá, Quintana Roo. Reporte de actividades 1975”, Cobá: un sitio maya en Quintana Roo, pp. 1-103. México: Instituto Nacional de Antropología e Historia, Dirección de Centros Regionales (Cuadernos de los Centros Regionales, 26).

1981 Los caminos de Cobá y sus implicaciones sociales. Proyecto Cobá. México: Instituto Nacional de Antropología e Historia, Centro Regional del Sureste (Colección Científica).

1987 "Arquitectura doméstica en Cobá”, Cobá, Quintana Roo. Análisis de dos unidades habitacionales mayas, pp. 25-67, Linda Manzanilla (ed.). México: Universidad Nacional Autónoma de México, Instituto de Investigaciones Antropológicas (Serie Antropológica, 82).

Benavides Castillo, Antonio y Linda Manzanilla

1987 "Introducción: estudio de centros urbanos", Cobá, Quintana Roo. Análisis de dos unidades habitacionales mayas, pp. 11-23, Linda Manzanilla (ed.). México: Universidad Nacional Autónoma de México, Instituto de Investigaciones Antropológicas (Serie Antropológica, Arqueología, 82).

Braswell, Geoffrey E.

1997 "El intercambio prehispánico en Yucatán, México”, X Simposio de Investigaciones Arqueológicas en Guatemala, 1996, pp. 595-606, J. P. Laporte y H. Escobedo (eds.). Guatemala: Museo Nacional de Arqueología y Etnología.

Brumfiel, Elizabeth y Timothy K. Earle

1990 "Specialization, Exchange, and Complex Societies. An Introduction”, Specialization, Exchange and Complex Societies, pp. 1-9, Elizabeth Brumfiel y Timothy K. Earle (eds.). Cambridge: Cambridge University Press (New Directions in Archaeology).

Castillo Velasco, Elva Adriana y Shiat Alejandra Páez Torres

2015 "Los materiales conquiliológicos de un asentamiento en la Costa Oriental de Quintana Roo”, Archaeobios, 9: 100-116.

Cobos, Rafael

2010 "Conchas arqueológicas en el occidente de Yucatán: patrones de abastecimiento durante el Clásico Tardío y el Clásico Terminal”, Ecos del pasado: los moluscos arqueológicos de México, pp. 47-63, Lourdes Suárez y Adrián Velázquez (coords.). México: Instituto Nacional de Antropología e Historia (Colección Científica, 572).

Colón González, Marinés

2003 "Los objetos de concha del género Spondylus de Calakmul: un acercamiento a sus técnicas de manufactura”, tesis de maestría en Antropología. México: Universidad Nacional Autónoma de México, Facultad de Filosofía y Letras, Instituto de Investigaciones Antropológicas.

Con Uribe, María José

1996 "Informe de la segunda temporada. Proyecto Cobá”. México: Archivo Téc- 
nico de la Coordinación Nacional de Arqueología, Instituto Nacional de Antropología e Historia.

1998 "Informe de la tercera temporada 1997-1998. Proyecto Cobá”. México: Archivo Técnico de la Coordinación Nacional de Arqueología, Instituto Nacional de Antropología e Historia.

1999 "Informe de la cuarta temporada 1999. Proyecto Cobá”. México: Archivo Técnico de la Coordinación Nacional de Arqueología, Instituto Nacional de Antropología e Historia.

2000 "El juego de pelota en Cobá, Quintana Roo", Arqueología, 23: 27-50.

2005 "Informe de la octava temporada de campo. Proyecto Cobá". México: Archivo Técnico de la Coordinación Nacional de Arqueología, Instituto Nacional de Antropología e Historia.

2007 Cobá. Historia, arte y monumentos. México: Consejo Nacional para la Cultura y las Artes, Instituto Nacional de Antropología e Historia, Monclem Ediciones.

2010 "Informe de la temporada 2010. Proyecto Cobá". México: Archivo Técnico de la Coordinación Nacional de Arqueología, Instituto Nacional de Antropología e Historia.

Con Uribe, María José y María José Gómez Cobá

2008 "La asociación estela-altar en el grupo Macanxoc de Cobá”, Expedición, Historia y Antropología, 2 (2): 118-130.

Con Uribe, María José y José Manuel Ochoa

2003 "Informe de la sexta temporada del Proyecto Cobá". México: Archivo Técnico de la Coordinación Nacional de Arqueología, Instituto Nacional de Antropología e Historia.

2007 "Informe de la temporada 2007, Proyecto Cobá". México: Archivo Técnico de la Coordinación Nacional de Arqueología, Instituto Nacional de Antropología e Historia.

Con, María José, José Manuel Ochoa y María José Gómez Cobá

2004 "Informe de la séptima temporada. Proyecto Cobá”. México: Archivo Técnico de la Coordinación Nacional de Arqueología, Instituto Nacional de Antropología e Historia.

Con Uribe, María José y Octavio Esparza Olguín

2016 "Recovered History: Stela 11 of Coba”, The PARI Journal, XVII (1): 1-17.

Costin, Cathy Lynne

2007 "Phenomenological Classification and Lexical Semantics", Rethinking Craft Specialization in Complex Societies. Archaeological Analyses of the Social Meaning of Production, pp. 143-162, Zachary Hruby y Rowan K. Flad (eds.). Pennsylvania: American Anthropological Association (Archaeological Papers, 17).

Esparza Olguín, Octavio Quetzalcóatl

2016 "Estudios de los monumentos esculpidos de Cobá, Quintana Roo, y su contexto arqueológico", tesis de doctorado en Estudios Mesoamericanos. Mé- 
xico: Universidad Nacional Autónoma de México, Facultad de Filosofía y Letras, Instituto de Investigaciones Filológicas.

Flores Hernández, María y Manuel Eduardo Pérez Rivas

2006 "Apuntes para el estudio de la organización sociopolítica de la costa oriental de Quintana Roo", Nuevas perspectivas sobre la geografía política de los mayas, pp. 81-125, Tsubasa Okoshi, Lorraine Williams-Beck y Ana Luisa Izquierdo (eds.). México: Universidad Nacional Autónoma de México, Universidad Autónoma de Campeche, Foundation for the Advancement of Mesoamerican Studies, Inc.

Folan, William, Armando Anaya, Ellen R. Kintz, Laraine A. Fletcher, Raymundo Gonzalez, Jacinto May Hau y Nicolas Caamal Canche

2009 "Coba, Quintana Roo, Mexico: A Recent Analysis of the Social, Economic and Political Organization of a Major Maya Urban Center", Ancient Mesoamerica, 20: 59-70. DOI: https://doi.org/10.1017/S0956536109000054.

Gallardo Parrodi, Ma. de Lourdes

2014 "Las prendas de concha nacarada del Templo Mayor de Tenochtitlán", tesis de doctorado en Estudios Mesoamericanos. México: Universidad Nacional Autónoma de México, Facultad de Filosofía y Letras, Instituto de Investigaciones Filológicas.

Goldstein, Marilyn y Lourdes Suárez Diez

1997 Conchas Precolombinas: Mesoamerican Art Created from Seashells. Washington: Hillwood Art Museum, Long Island University.

Herskovits, Melville

1954 Antropología económica. México: Fondo de Cultura Económica.

Hohman, Bobbi Michael

2002 "Preclassic Maya Shell Ornament Production in the Belize Valley, Belize", tesis de doctorado. New Mexico: The University of New Mexico.

Inomata, Takeshi

2007 "Knowledge and Belief in Artistic Production by Classic Maya Elites", Rethinking Craft Specialization in Complex Societies: Archaeological Analysis of the Social Meaning of Production, pp. 129-141, Zachary Hruby y Rowan K. Flad (eds.), Pennsylvania: American Anthropological Association (Archaeological Papers, 17).

Instituto Nacional de Estadística, Geografía e Informática (INEGI)

2019 Mapa digital de México. <http://gaia.inegi.org.mx/mdm-client/?v=bGF0Ojly Ljk0ODQ4LGxvbjotOTcuMjM3NzksejoyLGw6YzQxMw> [consultado el 9 de julio de 2019].

The MUSSEL Project

2014 The Freshwater Mussels (Unionoida) of the World (and other less conse- 
quential bivalves) <http://mussel-project.uwsp.edu/fmuotwaolcb/north_ america.html > [consultada el 9 de julio de 2019].

Maldonado Cárdenas, Rubén

1995 "Los sistemas de caminos del norte de Yucatán”, Seis ensayos sobre antiguos patrones de asentamiento en el área maya, pp. 63-92, Ernesto Vargas (comp.). México: Universidad Nacional Autónoma de México, Instituto de Investigaciones Antropológicas.

Mannoni, Tiziano y Enrico Giannichedda

2004 Arqueología de la producción. Barcelona: Ariel Prehistoria.

McKillop, Heather I.

1987 "Wild Cane Cay: An Insular Classic Period to Posclassic Period Maya Trading Station", tesis para obtener el grado de Philosophy Doctor. Santa Barbara: University of California, University Microfilms.

Melgar Tísoc, Emiliano

2009 "La producción especializada de los objetos de concha en Xochicalco", tesis de maestría en Antropología. México: Universidad Nacional Autónoma de México, Facultad de Filosofía y Letras, Instituto de Investigaciones Antropológicas.

Melgar Tisoc, Emiliano R. y María del Rosario Domínguez Carrasco

2014 "Los artesanos de concha y la élite de Calakmul. Los objetos elaborados y sus técnicas de manufactura", Los investigadores de la cultura maya 2013, vol. 22, tomo II, pp. 203-219. Campeche: Universidad Autónoma de Campeche.

2017 "Los moluscos de Calakmul: procedencia, rutas de obtención y manufactura”, Los investigadores de la cultura maya. El comercio y otros temas, pp. 111-123, María del Rosario Domínguez, Miriam Judith Gallegos, Ricardo Armijo, Miriam Edith León (eds.). Campeche: Universidad Autónoma de Campeche.

Ministerio de Agricultura, Ganadería y Alimentación

2001 Mapa fisiográfico-geomorfológico de la República de Guatemala, a escala 1: 250,000, Memoria técnica. Guatemala: Unidad de políticas e información estratégica y programa de emergencia por desastres naturales.

Moholy-Nagy, Hattula

1997 "Middens, Construction Fill, and Offerings: Evidence for the Organization of Classic Period Craft Production at Tikal, Guatemala", Journal of Field Archaeology, 24 (3): 293-313.

Navarrete, Carlos, María José Con y Alejandro Martínez Muriel

1979 Observaciones arqueológicas en Cobá, Quintana Roo. México: Universidad Nacional Autónoma de México, Instituto de Investigaciones Filológicas, Centro de Estudios Mayas. 
Páez Torres, Shiat A.

2017 "Informe sobre la tipología y análisis de huellas de manufactura realizados al material malacológico procedente de Xcaret, Quintana Roo”. México: Proyecto Cobá, Instituto Nacional de Antropología e Historia.

Pérez de Heredia, Eduardo y Péter Bíró

2007 "Ceramics and Epigraphy: Coba and the History of Northern Yucatán AD 700-830". Manuscrito inédito. <https://www.academia.edu/21907081/ Ceramics_and_Epigraphy_Coba_and_the_history_of_Northern_Yucatán_

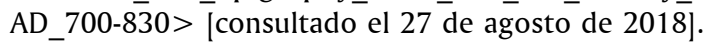

Reyes Espinosa, Alicia

2010 "La corrosión como técnica de manufactura en un objeto de concha de Kohunlich, Quintana Roo", Ecos del pasado: los moluscos arqueológicos de México, pp. 107-128, Lourdes Suárez y Adrián Velázquez (coords.). México: Instituto Nacional de Antropología e Historia (Colección Científica, 572).

Robles Castellanos, José Fernando

1990 La secuencia cerámica de la región de Cobá, Quintana Roo. México: Instituto Nacional de Antropología e Historia (Colección Científica, 184).

Schmidt, Peter, Mercedes de la Garza y Enrique Nalda (coords.)

1999 Los mayas. México: Consejo Nacional para la Cultura y las Artes, Instituto Nacional de Antropología e Historia, Landucci.

Suárez Díez, Lourdes

1974 Técnicas prehispánicas en los objetos de concha. México: Instituto Nacional de Antropología e Historia, Secretaría de Educación Pública.

2002 Tipología de los objetos prehispánicos de concha. México: Consejo Nacional para la Cultura y las Artes, Instituto Nacional de Antropología e Historia, Miguel Ángel Porrúa.

Vargas Pacheco, Ernesto

1997 Tulum. Organización político territorial de la costa oriental de Quintana Roo. México: Universidad Nacional Autónoma de México, Instituto de Investigaciones Antropológicas.

Velázquez Castro, Adrián

1999 Tipología de los objetos de concha del Templo Mayor de Tenochtitlán. México: Instituto Nacional de Antropología e Historia (Colección Científica, 392).

2012 "The Study of Shell Object Manufacturing Techniques from the Perspective of Experimental Archaeology and Work Traces", Archaeology, New Approaches in Theory and Techniques, pp. 229-250, Imma Ollich-Castanyer (ed.). InTechOpen. DOI: https://doi.org/10.5772/37679.

2016 "Proyecto Técnicas de manufactura de los objetos de concha del México prehispánico", ponencia presentada en el seminario del proyecto "Técnicas de manufactura de los objetos de concha del México prehispánico”. México: Museo del Templo Mayor. 
Velázquez Castro, Adrián, Emiliano Melgar Tísoc y AnneMarie Hocquenghem

2006 "Análisis de las huellas de manufactura del material malacológico de Tumbes, Perú", Bulletin del'Istitut Francais d'Etudes Andines, 35(1): 21-35. DOI: https://doi.org/10.4000/bifea.4730.

Velázquez Castro, Adrián y Emiliano Melgar Tísoc

2014 "Tipología de los objetos de Xcambó. Informe del análisis de la colección de objetos de concha de Xcambó", Archivo del proyecto "Técnicas de manufactura de los objetos de concha del México prehispánico”. México: Museo de Templo Mayor.

Vokes, Harold E. y Emily H. Vokes

1983 Distribution of Shallow-Water Marine Mollusca, Yucatán Peninsula, Mexico. New Orleans: Mesoamerican Ecology Institute, Tulane University (Middle American Research Institute, 54).

Elva Adriana Castillo Velasco. Mexicana. Licenciada en Arqueología por la Escuela Nacional de Antropología e Historia, actualmente cursa la maestría en el Programa de Posgrado en Estudios Mesoamericanos de la Universidad Nacional Autónoma de México. Su principal línea de investigación es la producción, uso, consumo y distribución prehispánica de objetos elaborados en concha, dentro de la cual desarrolla el proyecto "La producción de objetos de concha en las ofrendas de Cobá, Quintana Roo”. Entre sus publicaciones recientes se encuentran "Manufacture of Spondylus princeps objects in CALICA, Quintana Roo", "Manufactura de los objetos de concha de CALICA, Quintana Roo" y "Los materiales conquiliológicos de un asentamiento en la Costa Oriental de Quintana Roo". eacastillovelasco@gmail.com 